\title{
THE EFFECT OF ACETYLCHOLINE ON PULMONARY VASCULAR RESISTANCE AND LEFT ATRIAL PRESSURE IN MITRAL STENOSIS

\author{
BY
}

\author{
PAUL WOOD, E. M. BESTERMAN, M. K. TOWERS, AND M. B. McILROY \\ From the National Heart Hospital and the Institute of Cardiology, London
}

Received November 13, 1956

In mitral stenosis the obstruction to the circulation leads to a build-up of pressure in the left atrium which averages about $25 \mathrm{~mm}$. $\mathrm{Hg}$ in uncomplicated cases with critical stenosis requiring valvotomy (orifice $10 \times 5 \mathrm{~mm}$. or less). On effort the cardiac output increases and the left atrial pressure rises well above the osmotic pressure of the plasma, even up to 50 or $60 \mathrm{~mm}$. Familiar consequences of this situation include hæmoptysis, frank pulmonary œdema, and chronic interstitial œdema of the lungs.

As a rule, the pulmonary artery pressure rises passively and maintains a more or less normal pulmonary arterio-venous pressure gradient of about $10 \mathrm{~mm}$. (Fig. 1). The pulmonary vascular

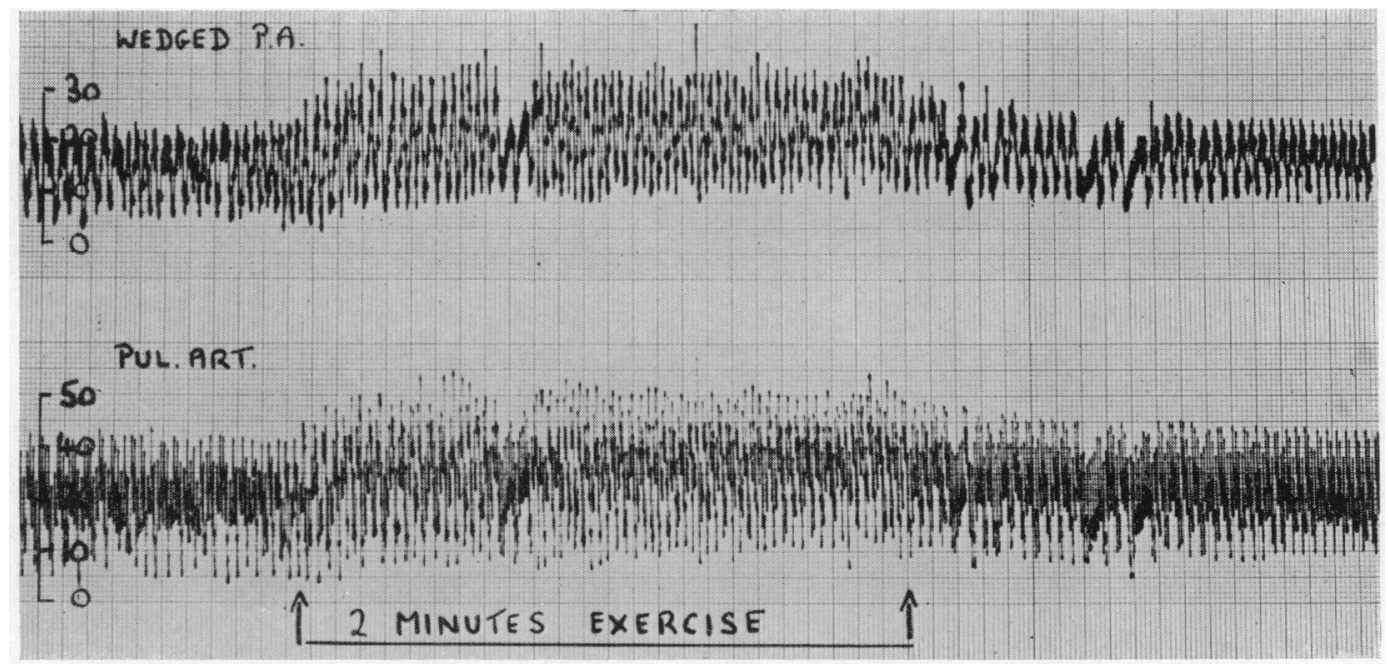

FIG. 1.-Passive pulmonary hypertension occurring on exercise in a case of mitral stenosis.

resistance in these simple cases of passive pulmonary hypertension is 0.5 to 5 units (40-400 dynes sec. $/ \mathrm{cm}^{-5}$ ). In a relatively small but important group of cases, however, pulmonary hypertension is of a different order and bears little relationship to the left atrial pressure, being due to intense pulmonary vasoconstriction (active pulmonary hypertension) or to widespread obstructive or obliterative changes in the small pulmonary arteries and arterioles (obstructive or obliterative pulmonary hypertension). Thus, in our own series of 350 cases of mitral stenosis subjected to valvotomy, the pulmonary vascular resistance was high (6-10 units) in 15 per cent and extreme (10-30 units) in 14 per cent. The cases with an extreme resistance behaved differently from 
uncomplicated cases of mitral stenosis, and suggested that a sufficiently high resistance protected the pulmonary capillaries and venous radicles from developing dangerously high pressures, even in the presence of an orifice as small as $5 \times 3 \mathrm{~mm}$. Hg (Lewis et al., 1952; Wood, 1954). The chief evidence on which this conclusion was based may be recapitulated as follows.

(1) A history of pulmonary apoplexy was obtained in 25 per cent of uncomplicated cases of mitral stenosis, but in only 12 per cent of those with a high resistance; recent congestive hæmoptysis occurred in 16 per cent of uncomplicated cases, but in only 4 per cent of those with a high resistance.

(2) Pulmonary œdema occurred in 10 per cent of the series. The pulmonary vascular resistance averaged 2.9 in these cases and never exceeded 5.2 units; in cases of equal or greater severity with no history of pulmonary œdema or paroxysmal cardiac dyspnœa or orthopnœa, the resistance averaged $9 \cdot 2$ units.

(3) Radiological evidence of chronic interstitial œdema of the lungs bore an inverse relationship to the pulmonary vascular resistance (Fig. 2). Typical skiagrams, one from a relatively low and the other from a high resistance case, are illustrated in Fig. 3 and 4.

(4) In cases of more or less equal severity in respect of the degree of stenosis, the left atrial pressure itself was also inversely related to the pulmonary vascular resistance (Fig. 5). The mechanism was attributed to the damping effect of a high resistance on the cardiac output (Fig. 6).

That functional pulmonary vasoconstriction plays an important part in initiating and maintaining the high resistance was suggested by the absence of a previous history of pulmonary
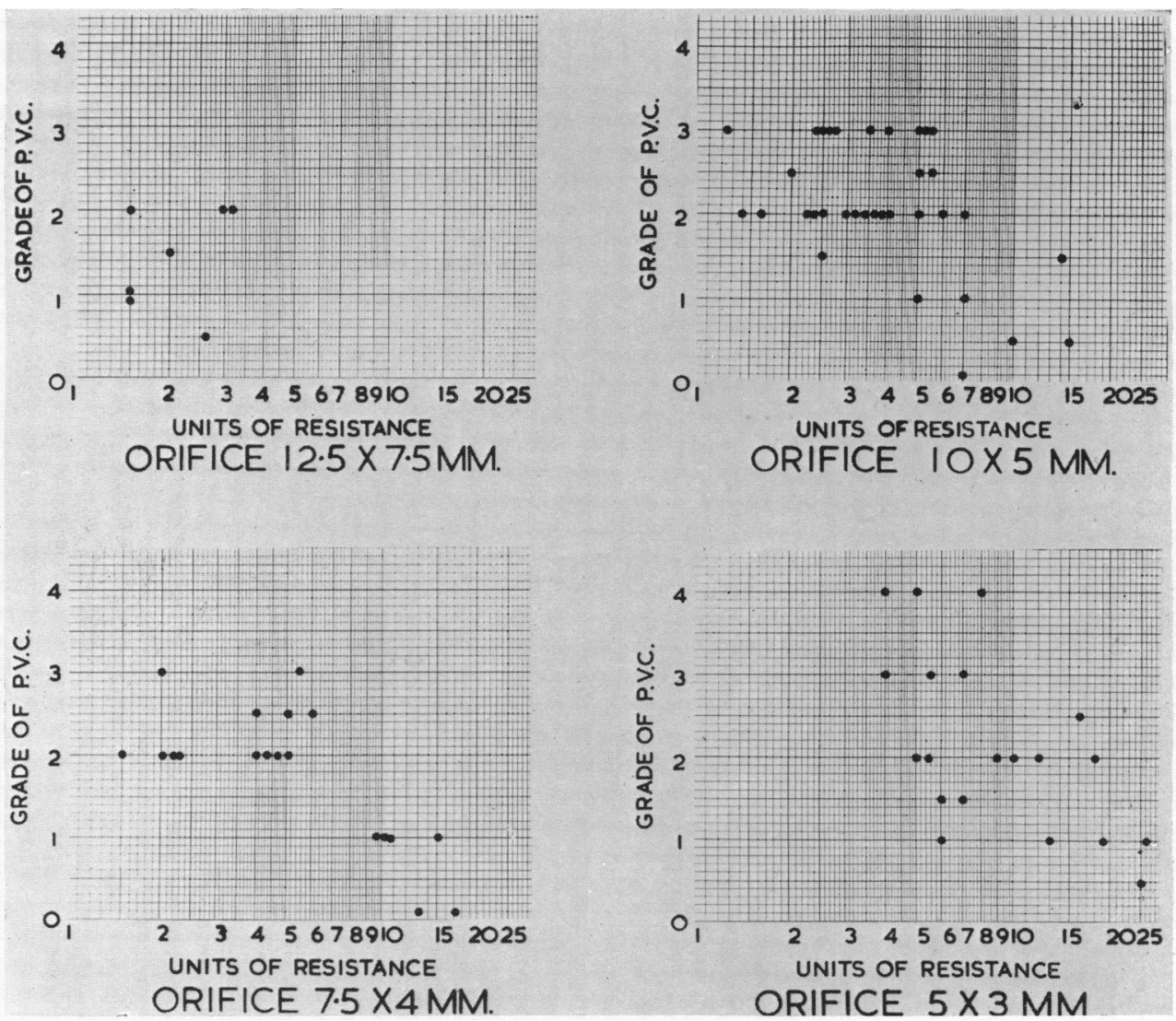

FIG. 2.-Chart, showing an inverse relationship between pulmonary venous congestion and the pulmonary vascular resistance in cases of mitral stenosis. 


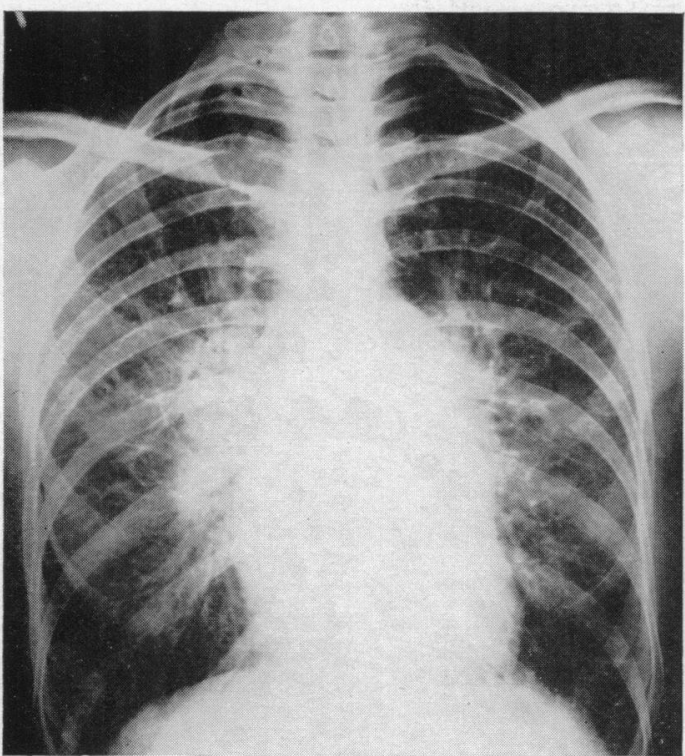

FIG. 3.-Skiagram, showing chronic interstitial œdema of the lung (pulmonary venous congestion) in a case of mitral stenosis.

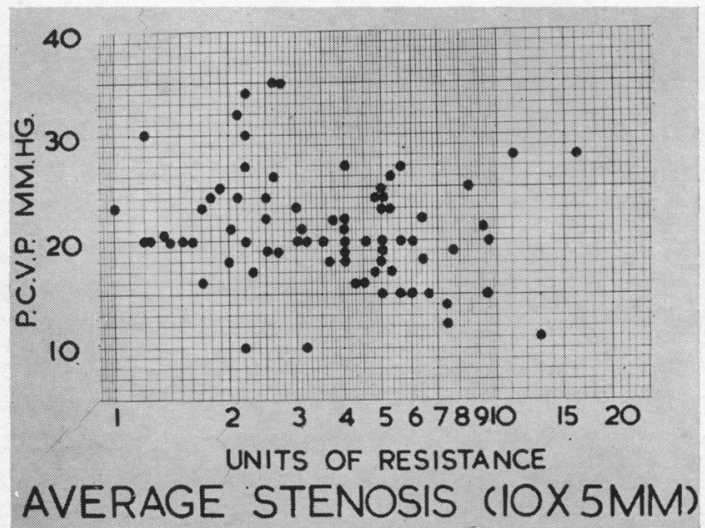

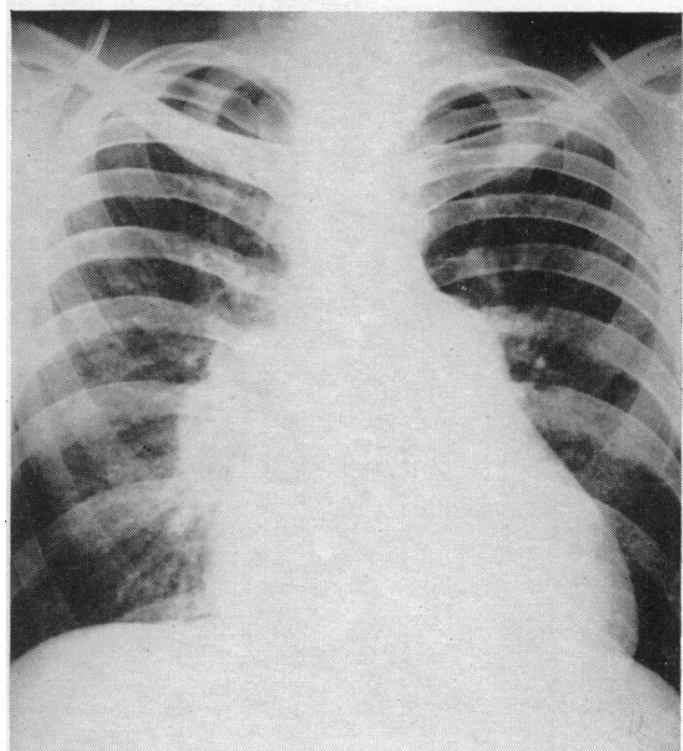

FIG. 4.--Skiagram of a case of mitral stenosis with an extreme pulmonary vascular resistance, showing minimal pulmonary venous congestion.

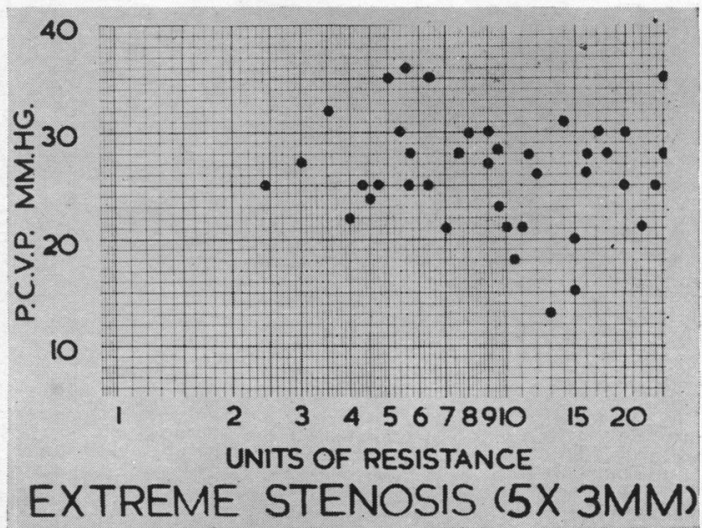

FIG. 5.-Chart, showing an inverse relationship between the mean left atrial pressure and the pulmonary vascular resistance in cases of mitral stenosis.

congestive symptoms in 80 per cent of the cases, by the fact that the average age of high resistance cases ( 39 years) was no higher than that of relatively low resistance cases with an equivalent degree of stenosis (39 years), and by extensive clinical and physiological evidence that the resistance commonly fell greatly after technically successful valvotomy.

The present paper deals with an attempt to test both parts of the thesis experimentally. If the concept that a high pulmonary vascular resistance is protective in the sense previously defined is correct, then lowering the resistance should result in raising the left atrial pressure and the cardiac output; secondly, if active pulmonary vasoconstriction is playing the part assigned to it, then the administration of a suitable pulmonary vasodilator should result in an appreciable fall in resistance. Ideally, the pulmonary vasodilator should be as selective as possible, so that it does not alter pulmonary or systemic venous tone or the systemic peripheral resistance. It was believed that 


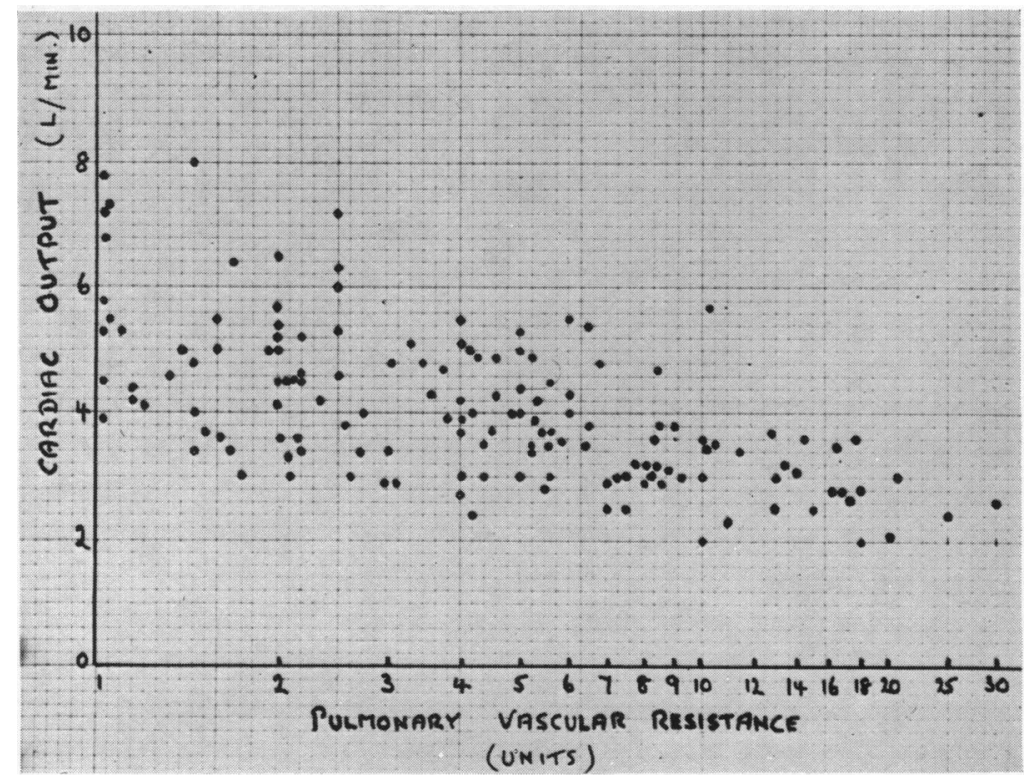

FIG. 6.-Chart, showing the braking effect of a high pulmonary vascular resistance on the cardiac output in cases of mitral stenosis.

acetylcholine might fulfil these criteria if injected directly into the pulmonary artery in a dose large enough to dilate the small pulmonary arteries and arterioles, yet small enough to be inactivated by the time it reached the systemic circulation. In fact this selective effect was usually achieved with a dose of 1 to $1.5 \mathrm{mg}$.

Method. A double lumen catheter was passed into the pulmonary artery so that the opening of the proximal barrel lay just distal to the pulmonary valve. Acetylcholine injected through this proximal barrel was expected to pass into both left and right pulmonary arteries. The proximal barrel was also used to obtain samples of mixed venous blood from the pulmonary trunk. The opening of the distal barrel lay well out in one or other pulmonary artery, but never far enough to wedge, so that the pulmonary artery pressure could be measured through this barrel. A second single lumen catheter was used to obtain the wedge pressure (Fig. 7). Two Riley needles were inserted into suitable arteries, one to record the systemic blood pressure, the other to obtain arterial samples. Oxygen consumption was measured by collecting 3 or 5 minute samples of expired air in a Douglas bag 5 minutes before, immediately after, and 5 minutes after the injection, two sets of simultaneous arterial and pulmonary artery samples being obtained during each period. In view of its instability acetylcholine was freshly prepared immediately before it was required. The initial dose was usually $1 \mathrm{mg}$. and was injected abruptly. If this proved insufficient to lower the pulmonary artery pressure appreciably, the procedure was repeated using $1.5 \mathrm{mg}$., and if there was still no effect $2 \mathrm{mg}$. was given. The usual critical dose was $1.5 \mathrm{mg}$. In view of the rapid inactivation of acetylcholine tests could be repeated, if necessary, within a few minutes.

\section{RESULTS}

Three cases of primary pulmonary hypertension served to demonstrate the selective action of acetylcholine so administered. Its effect in these three cases was similar (Fig. 8 and 9). The pulmonary artery pressure fell by an average of $37 / 20 \mathrm{~mm} . \mathrm{Hg}$, to a little over half the original pressure; the cardiac output rose by 0.5 to 1.0 litre per minute $(15-20 \%)$; the pulmonary vascular resistance fell from an average of 12.3 units to an average of 6.6 units. In two of the cases the systemic blood pressure rose $15 / 5 \mathrm{~mm}$., and the heart rate slowed 10 to 15 beats per minute; in the third case the blood pressure fell $3 / 5 \mathrm{~mm}$. $\mathrm{Hg}$ indicating a slight systemic effect. 


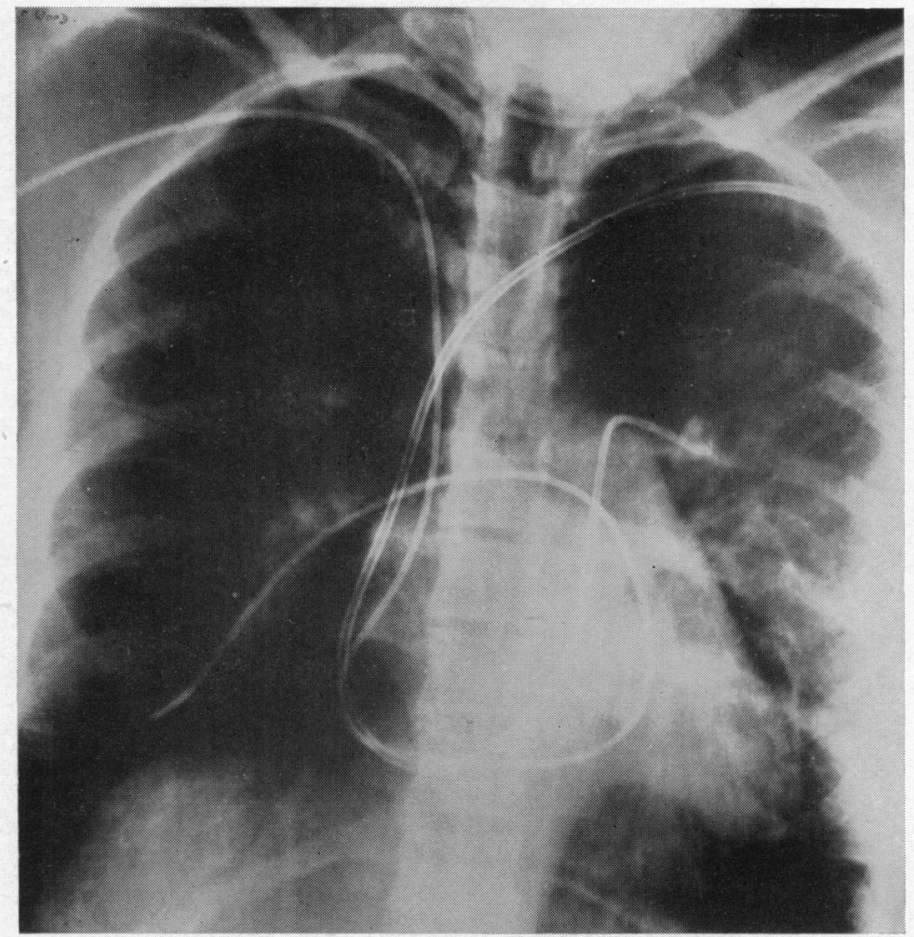

FIG. 7.-Skiagram, showing a double lumen catheter with its tip in the left pulmonary artery and the end of the proximal barrel just beyond the pulmonary valve; a single lumen catheter is wedged in a peripheral branch of the right pulmonary artery.

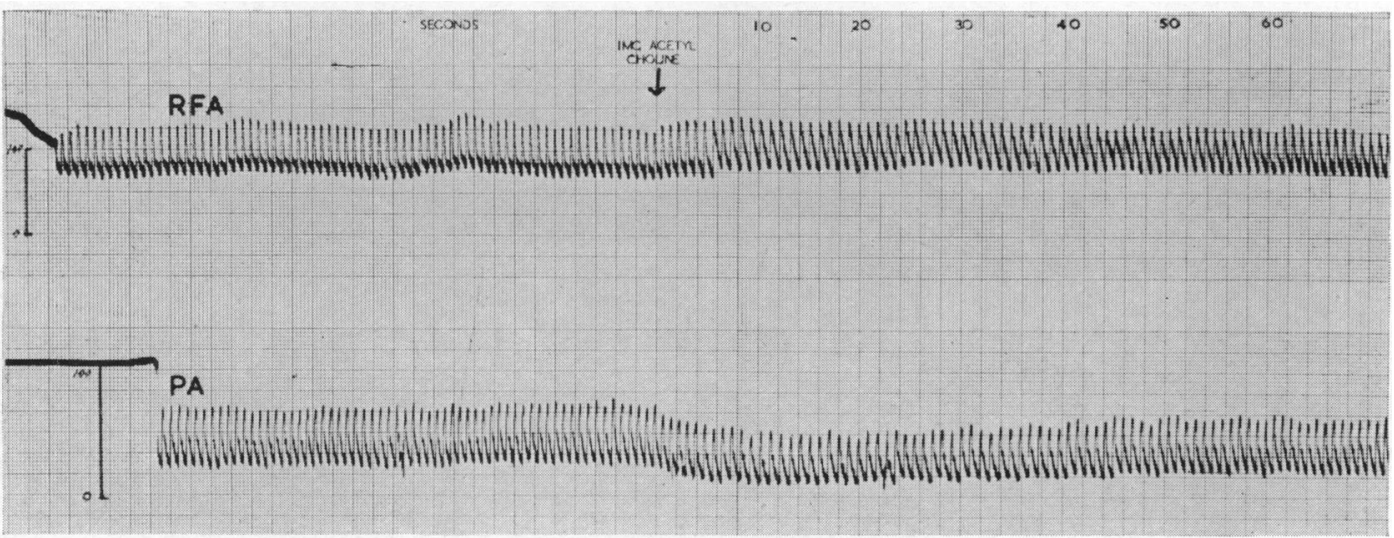

Fig. 8.-Pressure pulses from the pulmonary artery and femoral artery in a case of primary pulmonary hypertension, illustrating the typical response to acetylcholine.

Nine cases of mitral stenosis were studied (see table). In two there was no effect. The pulmonary artery pressure fell in each of the other seven, the drop averaging $15 / 8 \mathrm{~mm}$. $\mathrm{Hg}$; simultaneously the wedge pressure rose 3 to $5 \mathrm{~mm}$. in the five cases in which it was recorded: the catheter could not be wedged in the other two, owing to lack of sufficient tapering-a common difficulty in cases with a high pulmonary vascular resistance. Two typical graphs are illustrated (Fig. 10 and 11). The pulmonary vascular resistance fell from an average of $9 \cdot 4$ units to an average of $5 \cdot 4$ units. 


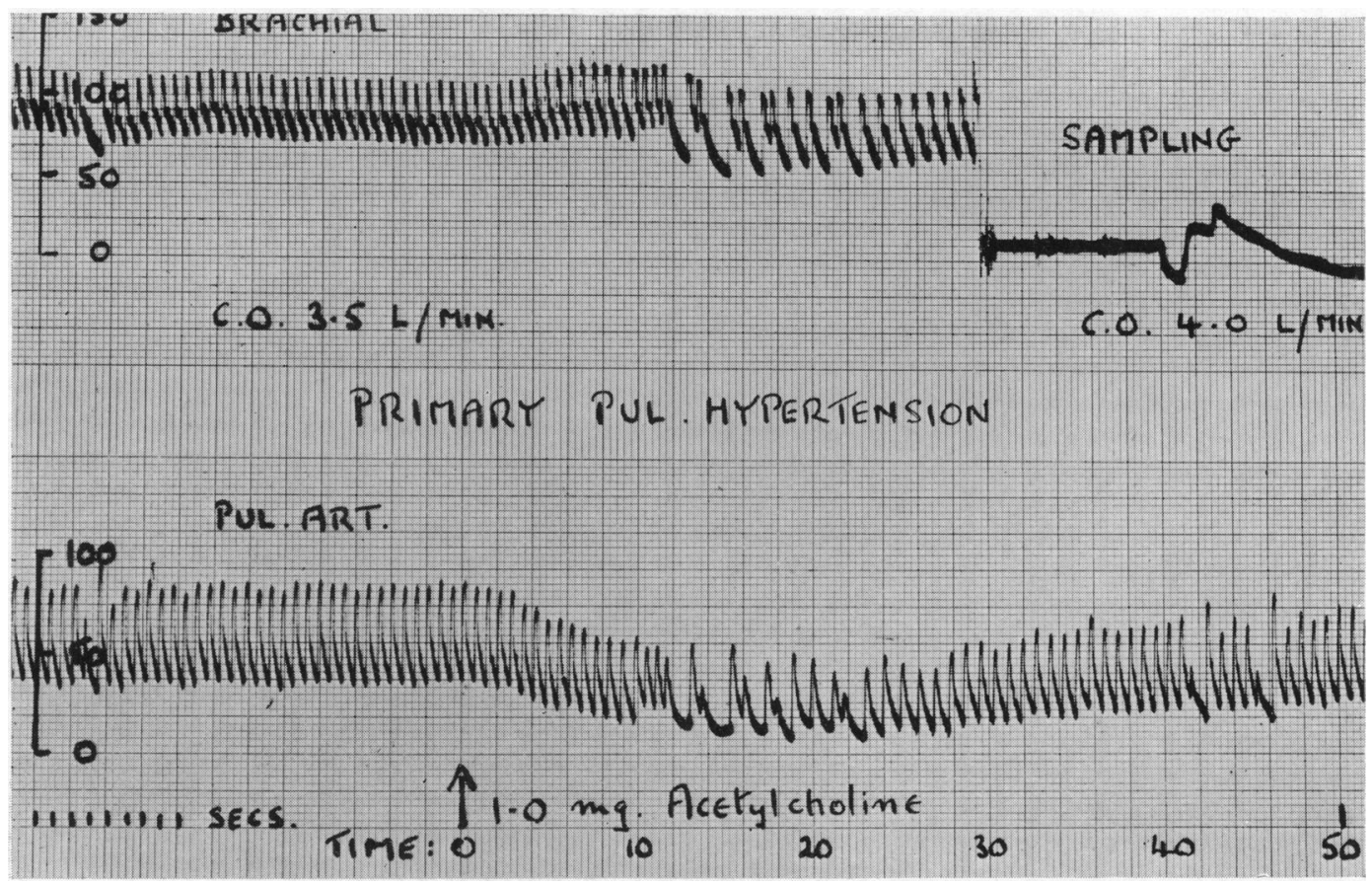

FIG. 9.-Pressure pulses from the pulmonary and brachial arteries in a case of primary pulmonary hypertension, showing a large fall in pulmonary vascular resistance following the injection of acetylcholine; the secondary fall in brachial artery pressure is due to a slight systemic effect of acetylcholine which in this case has not been totally inactivated during its passage through the lungs. Time in seconds.

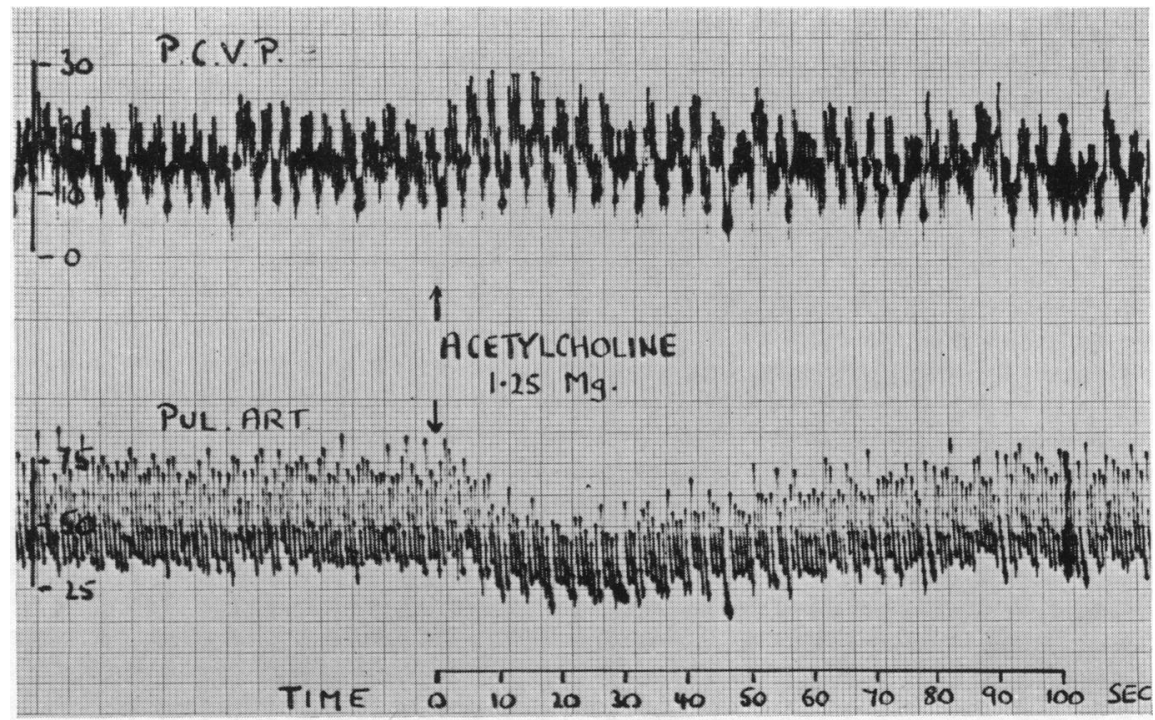

FIG. 10.-Simultaneous pulmonary artery and indirect left atrial pressure tracings from a case of mitral stenosis, showing a rise in left atrial pressure as the pulmonary vascular resistance falls.

The systemic blood pressure rose 5-10 $\mathrm{mm}$. in three cases, and fell by a similar amount in two, presumably as a result of insufficient inactivation of acetylcholine. It did not change in the two in which the pulmonary artery pressure did not fall, and it was not recorded in the other two. 


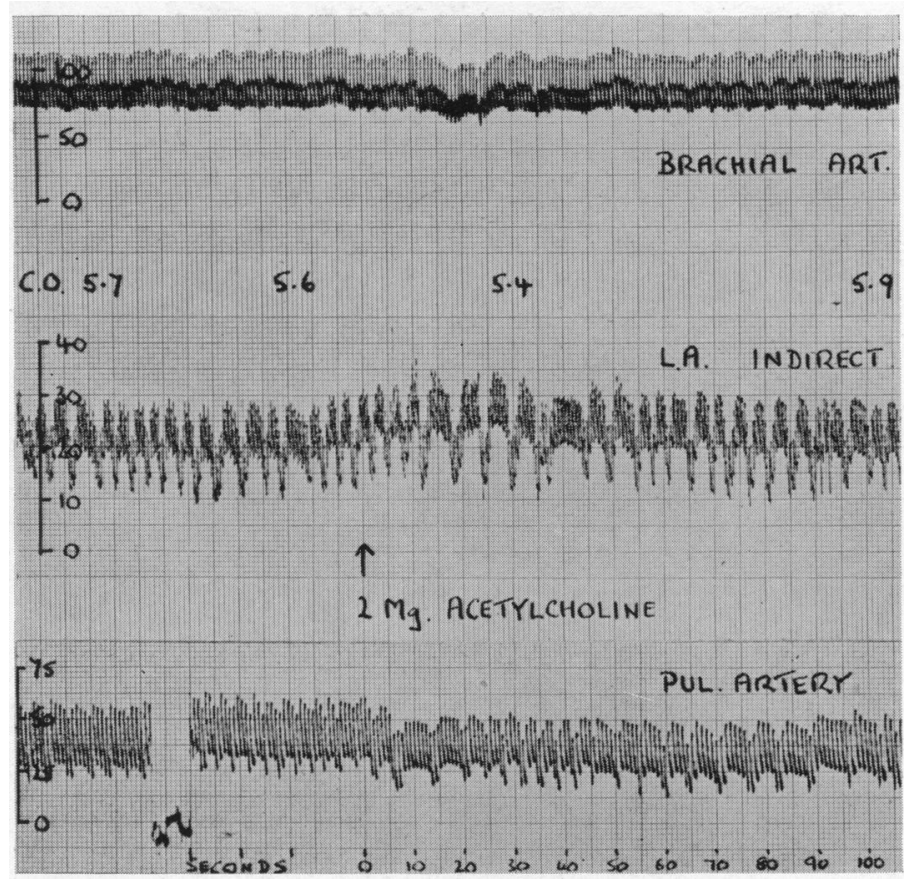

FIG. 11.-A second example, showing the effect of acetylcholine on pulmonary artery and left atrial pressure pulses in a case of mitral stenosis.

No convincing change in cardiac output was demonstrated, but it is difficult to measure small transient changes in output by means of the Fick principle. When the systemic blood pressure rises after acetylcholine, however, a rise of output may be assumed; and when there is no change of heart rate a rise in left atrial pressure must be followed by a rise of output.' In fact, the heart rate did not alter except in one case in which it fell from 84 to 72 beats a minute.

TABLE I

Effect of Acetylcholine on Nine Cases of Mitral Stenosis

\begin{tabular}{|c|c|c|c|c|c|c|c|c|c|c|c|c|c|}
\hline \multirow[t]{2}{*}{ Case } & \multirow[t]{2}{*}{$\begin{array}{l}\text { Dose } \\
\text { (mg.) }\end{array}$} & \multirow{2}{*}{\multicolumn{2}{|c|}{$\begin{array}{l}\text { Pul. vasc. } \\
\text { resistance } \\
\text { (units) } \\
\text { before after }\end{array}$}} & \multirow{2}{*}{\multicolumn{2}{|c|}{$\begin{array}{c}\text { Pulmonary } \\
\text { arterial pressure } \\
(\mathrm{mm} . \mathrm{Hg}) \\
\text { before after }\end{array}$}} & \multicolumn{2}{|c|}{$\begin{array}{l}\text { Indirect (wedge) } \\
\text { left atrial pressure } \\
\text { (mm. Hg) } \\
\text { before after }\end{array}$} & \multirow{2}{*}{\multicolumn{2}{|c|}{$\begin{array}{l}\text { Cardiac } \\
\text { output } \\
\text { (1/min.) } \\
\text { before after }\end{array}$}} & \multirow{2}{*}{\multicolumn{2}{|c|}{$\begin{array}{c}\text { Systemic blood } \\
\text { pressure } \\
(\mathrm{mm} . \mathrm{Hg}) \\
\text { before after }\end{array}$}} & \multirow{2}{*}{\multicolumn{2}{|c|}{$\begin{array}{l}\text { Heart rate } \\
\text { per. minute } \\
\text { before after }\end{array}$}} \\
\hline & & & & & & & & & & & & & \\
\hline $\begin{array}{l}1 \\
2 \\
3 \\
4 \\
5 \\
6 \\
7 \\
8 \\
9\end{array}$ & $\begin{array}{l}1.0 \\
1.0 \\
1.5 \\
2.0 \\
2.0 \\
1.5 \\
1.0 \\
1.25 \\
1.25\end{array}$ & $\begin{array}{r}4 \cdot 8 \\
4 \cdot 5 \\
17 \cdot 0 \\
9 \cdot 0 \\
2 \cdot 5 \\
5 \cdot 0 \\
16 \cdot 0 \\
12 \cdot 0 \\
14 \cdot 0\end{array}$ & $\begin{array}{r}2 \cdot 0 \\
4 \cdot 5 \\
17 \cdot 0 \\
5 \cdot 5 \\
1 \cdot 3 \\
3 \cdot 7 \\
12 \cdot 0 \\
9 \cdot 0 \\
4 \cdot 0\end{array}$ & $\begin{array}{r}55 / 25 \\
50 / 30 \\
120 / 60 \\
45 / 25 \\
60 / 32 \\
80 / 45 \\
133 / 50 \\
87 / 37 \\
75 / 38\end{array}$ & $\begin{array}{r}40 / 17 \\
50 / 30 \\
120 / 60 \\
40 / 20 \\
50 / 27 \\
65 / 38 \\
113 / 38 \\
75 / 30 \\
50 / 25\end{array}$ & $\begin{array}{l}17 \\
14 \\
13 \\
22 \\
21 \\
27 \\
20 \\
20\end{array}$ & $\begin{array}{l}\overline{14} \\
16 \\
28 \\
25 \\
30 \\
\frac{24}{24}\end{array}$ & $\begin{array}{l}3 \cdot 7 \\
6 \cdot 0 \\
2 \cdot 2 \\
5 \cdot 6 \\
6 \cdot 3 \\
3 \cdot 1 \\
3 \cdot 0 \\
2 \cdot 6\end{array}$ & $\begin{array}{l}\overline{6 \cdot 0} \\
\overline{-} \\
\overline{5 \cdot 9} \\
\overline{3 \cdot 0} \\
\overline{2 \cdot 4}\end{array}$ & $\begin{array}{ll}180 / 100 \\
100 / 60 & 1 \\
130 / 70 & 1 \\
120 / 60 & \\
115 / 75 & 1 \\
120 / 70 & 1 \\
160 / 105 & 1 \\
120 / 60 & 1 \\
120 / 65 & 1\end{array}$ & $\begin{array}{l}\overline{1} \overline{100 / 60} \\
130 / 70 \\
\overline{100 / 60} \\
125 / 75 \\
170 / 110 \\
112 / 60 \\
125 / 70\end{array}$ & $\begin{array}{r}108 \\
69 \\
48 \\
72 \\
72 \\
66 \\
96 \\
84 \\
78\end{array}$ & $\begin{array}{r}104 \\
72 \\
48 \\
72 \\
72 \\
66 \\
96 \\
72 \\
78\end{array}$ \\
\hline
\end{tabular}

\section{SUMMARY AND CONClUSIONS}

We have recapitulated the reasons for believing that a high pulmonary vascular resistance in cases of mitral stenosis is initially functional and protects the pulmonary venous system from developing dangerously high pressures. 
A method was devised for testing the thesis experimentally. Acetylcholine in doses of 1 to $1.5 \mathrm{mg}$. proved to be a powerful selective pulmonary vasodilator when injected directly into the pulmonary artery, and was virtually inactivated by the time it reached the systemic circulation.

Release of pulmonary vasoconstrictor tone halved the pulmonary vascular resistance in three cases of primary pulmonary hypertension; simultaneously the cardiac output and blood pressure rose.

In mitral stenosis a similar large fall in pulmonary vascular resistance was usually observed, and simultaneously the left atrial pressure rose. There was little change in cardiac output, blood pressure, and pulse rate.

It is concluded that in mitral stenosis the high pulmonary vascular resistance is at least partly functional, and is protective in the sense defined. Whether the reaction is purposeful or accidental is irrelevant to the thesis.

\section{REFERENCES}

Lewis, B. M., Gorlin, R., Houssay, H. E., Haynes, F. W., and Dexter, L. (1952) Amer. Heart J., 43, 2. Wood, P. (1952) Brit. med. Bull., 8, 348.

- (1954) Brit. med. J., 1, 1015 and 1113. 